\title{
FOLIAR APPLICATION OF GLYCINEBETAINE (GB) ALLEVIATES THE CADMIUM (Cd) TOXICITY IN SPINACH THROUGH REDUCING Cd UPTAKE AND IMPROVING THE ACTIVITY OF ANTI-OXIDANT SYSTEM
}

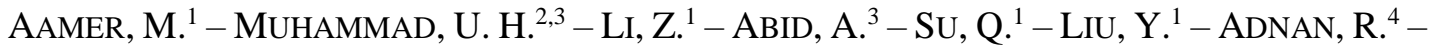 \\ MUHAMMAD, A. U. K. ${ }^{2}-$ TAHIR, A. K. ${ }^{2}-$ HUANG, G. ${ }^{*}$ \\ ${ }^{1}$ Research Center on Ecological Sciences, Jiangxi Agricultural University, \\ Nanchang 330045, China \\ ${ }^{2}$ Department of Agronomy, University of Agriculture, Faisalabad, Pakistan \\ ${ }^{3}$ Department of Agricultural and Food Sciences, University of Bologna, Italy
}

${ }^{4}$ Key Laboratory of Crop Physiology, Ecology and Genetic Breeding, Ministry of Education, Jiangxi Agricultural University, Nanchang 330045, China

*Corresponding author

e-mail:hgqjxes@sina.com

(Received 11 ${ }^{\text {th }}$ Jul 2018; accepted 28 ${ }^{\text {th }}$ Sep 2018)

\begin{abstract}
A pot experiment was conducted to determine the effect of foliar applied glycinebetaine (GB) against cadmium $(\mathrm{Cd})$ stress tolerance in spinach. The study consisted of three concentrations of $\mathrm{Cd}$ i.e., 0,25 and $50 \mathrm{mg} \mathrm{kg}^{-1}$ and foliar application of GB glycinebetaine i.e., 0 and $25 \mathrm{mM}$. The results indicated that $\mathrm{Cd}$ stress considerably reduced the root growth, shoot growth, fresh biomass, dry biomass, chlorophyll a and b contents. Moreover, the foliar application of GB under Cd stress considerably increased the root and shoot growth, fresh and dry biomass production, chlorophyll a and b contents and activity of anti-oxidant enzymes i.e., malondialdehyde (MDA) and ascorbate per oxidase (APX) and reduced the accumulation of $\mathrm{Cd}$ in the roots and leaves of spinach. In conclusion, foliar application of GB alleviates the $\mathrm{Cd}$ toxicity in spinach through reduction in $\mathrm{Cd}$ uptake and improvement in anti-oxidant defensive system under Cd stress.
\end{abstract}

Keywords: cadmium stress, spinach, glycinebetaine, anti-oxidant enzymes, chlorophyll

\section{Introduction}

Heavy metals enter into our environment thorough human activities, deposition of atmospheric volcanic eruptions and weathering of parent material (Wagner, 1993). These heavy metals are hazardous for the crops and they enter into the human food chain through eating these crops (Adrees et al., 2015). Amongst heavy metals, $\mathrm{Cd}$ is the most injurious for the crops and Cd toxicity is considerably reducing the food and soil quality globally (Rehman et al., 2015).

$\mathrm{Cd}$ stress caused various physiological and morphological disorders in the crop plants (Farooq et al., 2016). Likewise, it reduced plant growth, biomass production, rate of photosynthesis, and uptake of water and nutrients (Choppala et al., 2014). Moreover, $\mathrm{Cd}$ stress produced free radicals and caused oxidative damage in plants through production of ROS which imparts the negative effects on the proteins, amino acids and other molecules (Rizwan et al., 2016). Additionally, Cd stress also disrupts the electron transport chain, integrity of enzymatic activities and caused alterations in the DNA (Choppala et al., 2014). 
Different strategies are being used globally in order to reduce the uptake and toxicity of heavy metals. Amongst these strategies, use of osmo-protectants is one of the promising approach which considerably reduced the heavy metal toxicity in plants. Glycinebetaine (GB) is ammonium compound which is found in the plants as well as the animals however, its concentration may vary among the plant species (Chen and Murata, 2011). GB is environmental friendly, soluble in water and it has no toxic effects (Makela et al., 1996) and its concentration in plants considerably increased under the various kind of abiotic stresses (Dhir et al., 2012). In spinach GB is detectable in normal as well as the stress conditions however, its accumulation is not enough to protect plants from abiotic stresses (Sulpice et al., 1996). Therefore, the exogenous application of GB can ameliorate the adverse effects of different abiotic stress (Islam et al., 2010; Giri, 2011). Recently, Hasanuzzaman et al. (2014) reported that GB increased the salt tolerance in the rice plants through improving anti-oxidant enzymes activities. Likewise, foliage feeding of GB increased the drought tolerance in wheat by improving water uptake and rate of photosynthesis and transpiration (Raza et al., 2014). In another study, Molla et al. (2014) noticed that GB considerably decreased the oxidative stress in lentil (lens culinaris) through reduction in production of ROS. Moreover, Cao et al. (2013) and Rasheed et al. (2014) observed substantial improvement against the $\mathrm{Cd}$ stress tolerance in rice (Oryza Sativa) and wheat (Triticum aestivum) with the foliar applied GB.

Vegetables grown in pre-urban areas are highly contaminated with the heavy metals owing to application of city effluents (Liu et al., 2016). These vegetables contaminated with the heavy metals including $\mathrm{Cd}$, enters into human food chain and caused serious problems in human body. Spinach (Spinacia oleracea) is leafy vegetable with large leaf surface area and it has greater ability to accumulate heavy metals (Bagheri et al., 2013) and thus it increased the risks of human food chain contamination. Therefore, present investigation was conducted to determine the impact of foliar applied GB on spinach growth, biomass production, photosynthetic pigments and anti-oxidant defense system under Cd stress.

\section{Materials and Methods}

\section{Experimental site and growth conditions}

The current study was conducted at Research Center on Ecological Sciences, Jiangxi Agricultural University, Nanchang, Jiangxi in 2018. The pots having capacity of $5 \mathrm{~kg}$ were filled with the soil, and after that 10 spinach seeds were sown in each pot. The depth and diameter of pot was 16.5 and $20 \mathrm{~cm}$ respectively. In total 18 pots were used for experiment and three pots 6 for each treatment. After germination 3 spinach plants were left in the pot and rest of the pulled carefully. Each pot was fertilized with $250 \mathrm{ml}$ solution contained $\left.\left.0.84 \mathrm{~g} \mathrm{l}^{-1} \mathrm{~N}\left(\mathrm{NH}_{2}\right)_{2} \mathrm{CO}\right), 0.18 \mathrm{~g} \mathrm{l}^{-1} \mathrm{P}\left(\mathrm{NH}_{4}\right)_{2} \mathrm{HPO}_{4}\right)$, and $0.86 \mathrm{~g} \mathrm{l}^{-1} \mathrm{~K}$ $\left(\mathrm{K}_{2} \mathrm{SO}_{4}\right)$ after 10 days of germination.

\section{Treatments and experimental design}

The experiment was comprised of different cadmium concentrations i.e., 0,25 and $50 \mathrm{mg} \mathrm{kg}^{-1}$ of soil and foliar application of glycinebetaine i.e., 0 and $25 \mathrm{mM}$. Soil was spiked with $\mathrm{Cd}\left(\mathrm{NO}_{3}\right)_{2}$ according to the treatments four weeks before sowing of seeds in pots. The GB was applied as foliar spray in $0.1 \%$ Tween-20 solution at the rate of 0 and 
$25 \mathrm{mM}$ until after 15 days of sowing. The experiment was performed in the completely randomized in factorial arrangement.

\section{Plant sampling}

The harvesting was done after 45 days of germination. Three plants were uprooted and plant roots were washed with distilled water to remove the soil deposition. After that root and shoot length were measured with the scale and average was taken. The same plants were weighed to determine the fresh biomass yield per plot. After that these plants were cut into pieces and dried in oven until constant weight achieved to determine the dry biomass per plot.

\section{Biochemical analysis}

The root and shoot dried samples were taken and grinded with the help of grinder. 1 $\mathrm{g}$ of each sample of root and shoot was taken in conical flask. After that samples were digested by adding the $\mathrm{HNO}_{3}$ and $\mathrm{HClO}_{4}$ (3:1 ratio) on hot plate. The concentration of $\mathrm{Cd}$ in root and shoot samples were determined by atomic absorption spectrophotometer (PerkinElmer, Analyst 100, Waltham, USA) after calibrating the instrument using standard solution of $\mathrm{Cd}$. For determination of chlorophyll contents, $0.2 \mathrm{~g}$ of plant samples were extracted overnight with $80 \%$ acetone solution after that they were grinded and homogenized. The mixture was filtered, and the filtrates volume was made up to $25 \mathrm{ml}$ by adding the $80 \%$ acetone solution. Chlorophyll a and b contents were determined using the standard formula as described by the Arnon (1949). Likewise, the activities of MDA in root and leaf samples were measured by the standard procedures of the Bailly et al. (1996).

\section{Statistical analysis}

The data on growth, biomass, photosynthetic pigments and antioxidant enzymes were analyzed by Fisher's analysis of variance technique and difference amongst treatment means were compared using LSD at $5 \%$ probability level.

\section{Results}

\section{Growth and biomass attributes}

Cadmium (Cd) stress significantly decreased root and shoot length of spinach (Fig. 1 $A, B)$. Nonetheless maximum reduction in root and shoot length was noted in higher $\mathrm{Cd}$ stress (50 mg kg-1 soil) as compared to control. Furthermore, foliar application of glycinebetaine (GB) considerably improved the root and shoot length under different concentrations of $\mathrm{Cd}$ stress. Moreover, in control conditions foliar applied GB slight decreased the root length of spinach plant as compared to the Cd stress (Fig. 1 A). Foliage feeding of GB shows a significant impact on the biomass productivity. Maximum fresh and dry biomass was recorded with the foliar application of GB under no $\mathrm{Cd}$, stress, whilst minimum fresh and dry biomass was noticed in higher $\mathrm{Cd}$ stress (50 $\mathrm{mg} \mathrm{kg}^{-1}$ soil) without the foliar applied GB (Fig. 1 C, D). 

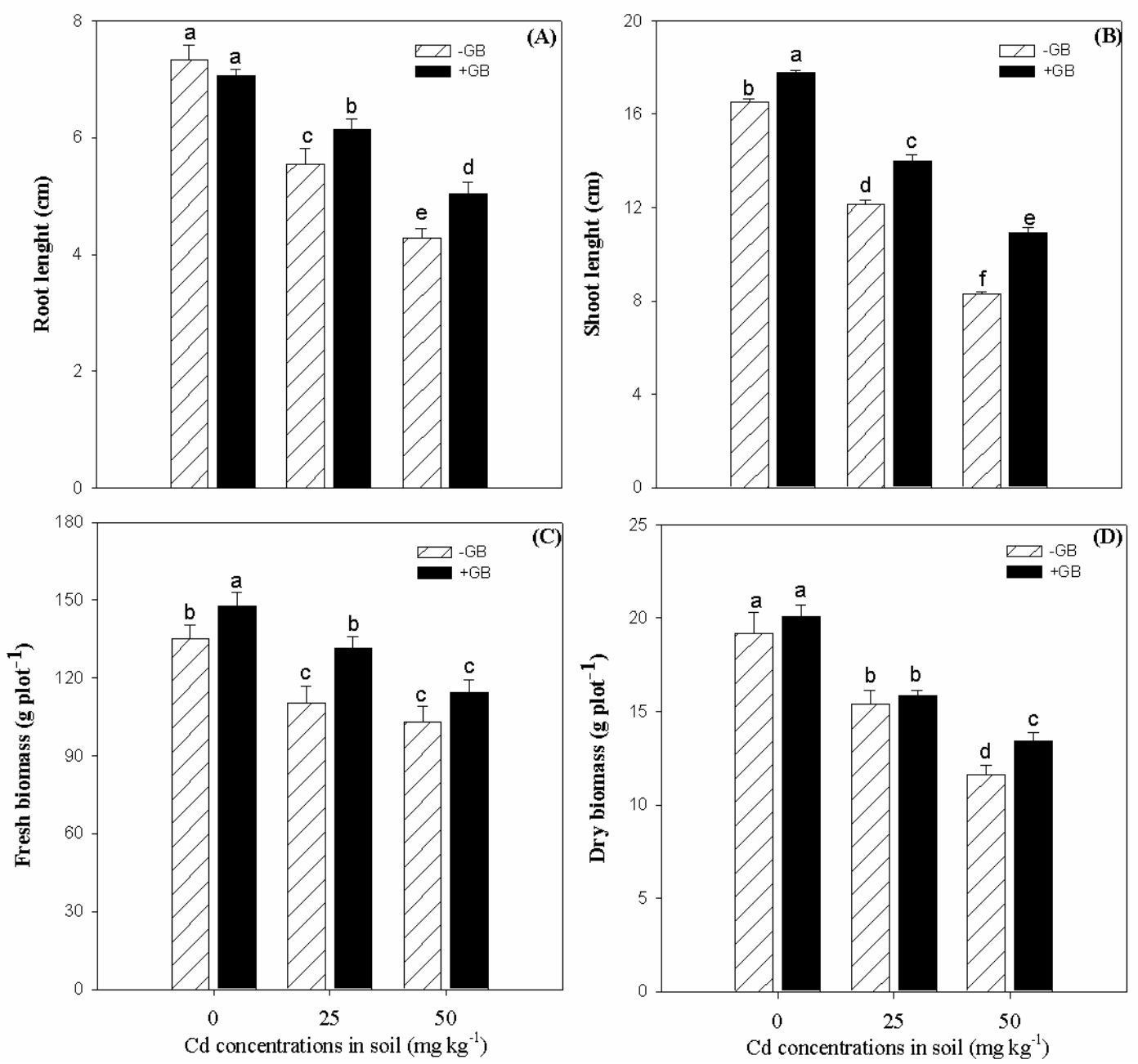

Figure 1. Effect of foliar applied $G B$ on the root length $(A)$, shoot length $(B)$, fresh biomass $(C)$ and dry biomass $(D)$ of spinach grown in different levels of $C d$ stress. Bars represents the $S E$ of three replications. -: No GB application, +: GB application

\section{Photosynthetic pigments}

$\mathrm{Cd}$ stress significantly decreased the chlorophyll contents as compared to no $\mathrm{Cd}$ stress (Fig. $2 \mathrm{~A}, \mathrm{~B}$ ). The maximum reduction in chlorophyll a and chlorophyll b contents was noted in soil spiked with the $\mathrm{Cd}$ at $50 \mathrm{mg} \mathrm{kg}^{-1}$, as compared to the lower Cd stress (Fig. 2 A, B). Foliar application of GB significantly increased the chlorophyll a and chlorophyll b contents under normal as well as the Cd stress conditions.

\section{Cadmium concentration in plant roots and leaf}

The results indicated that $\mathrm{Cd}$ concentration in plant roots and leaves was significantly increased with increasing in the $\mathrm{Cd}$ in the soil (Fig. $3 \mathrm{~A}, \mathrm{~B}$ ). Generally, Cd concentration was higher in the plant roots as compared to leaf. Foliar application of GB considerably decreased the $\mathrm{Cd}$ concentration in roots and leaves as compared to $\mathrm{Cd}$ stress conditions only (Fig. 3 A, B). 

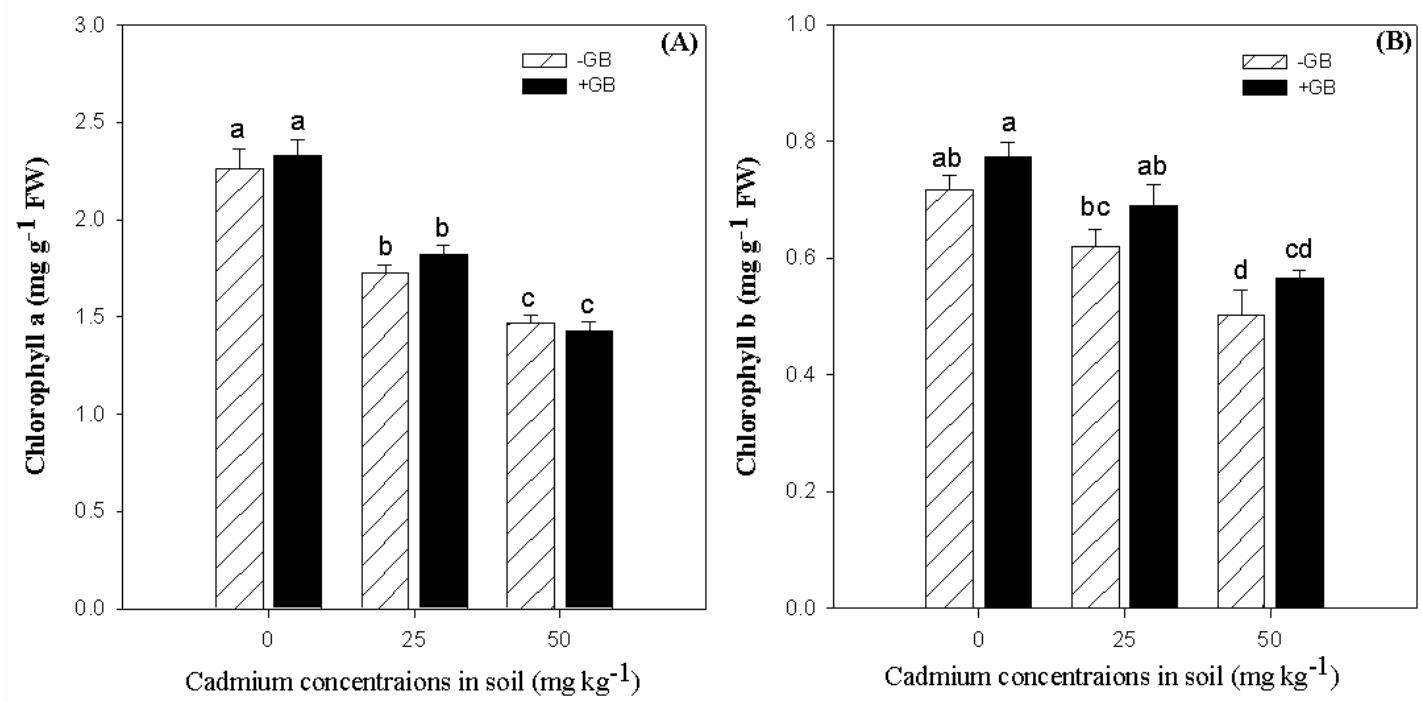

Figure 2. Effect of foliar applied GB on the chlorophyll a contents $(A)$ and chlorophyll $b$ contents $(B)$ of spinach grown in different levels of $C d$ stress. Bars represents the SE of three replications. -: No GB application, +: GB application
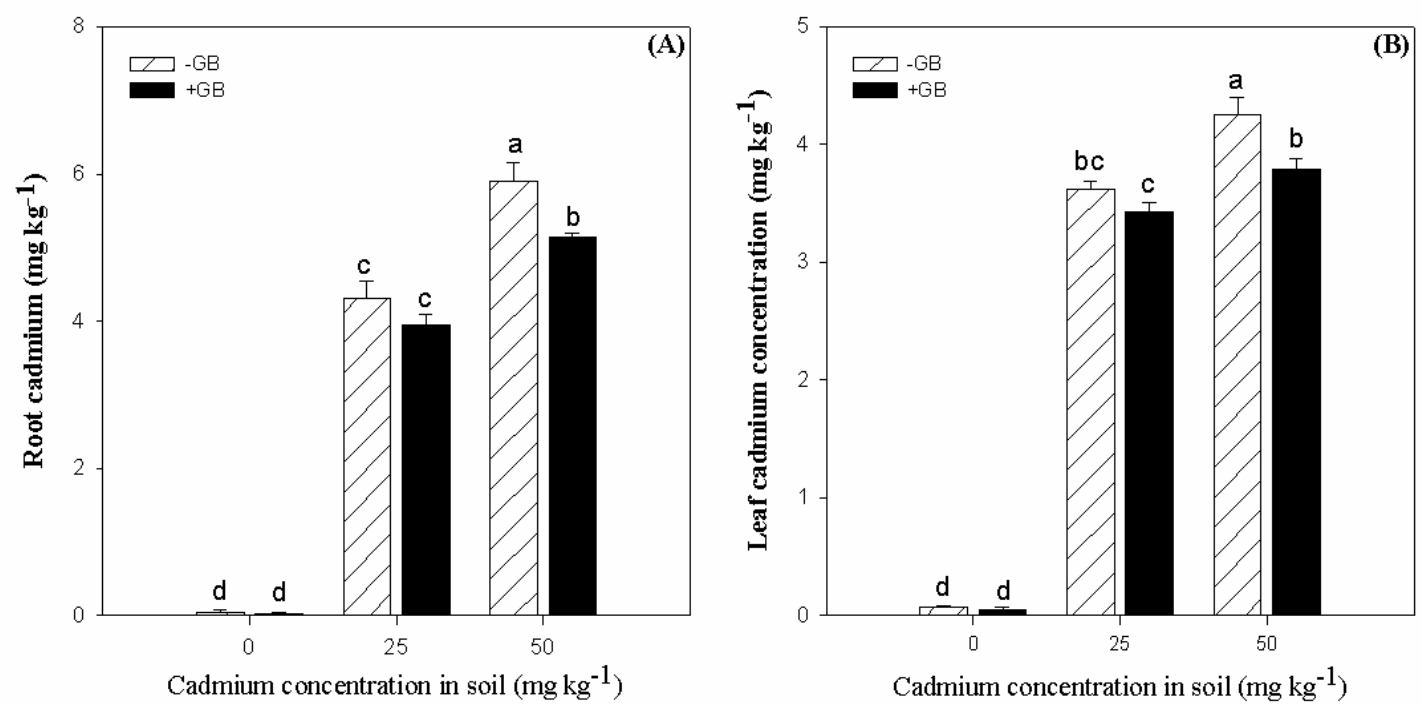

Figure 3. Effect of foliar applied $G B$ on the root $C d$ concentration $(A)$ and leaf $C d$ concentration (B) of spinach grown in different levels of Cd stress. Bars represents the SE of three replications. -: No GB application, +: GB application

\section{Antioxidant enzyme activities}

Cadmium stress led to significant alteration in activities of anti-oxidant enzymes in root and leaves of spinach plants (Fig. 4). The results indicated that as compared to the control the root and leaf APX and MDA activities significantly increased in response to Cd stress; give a clear indication of increase in activity of anti-oxidant enzymes under stress conditions. Furthermore, foliar applied GB clearly improved the root and leaf APX and MDA activities under the Cd stress conditions. 

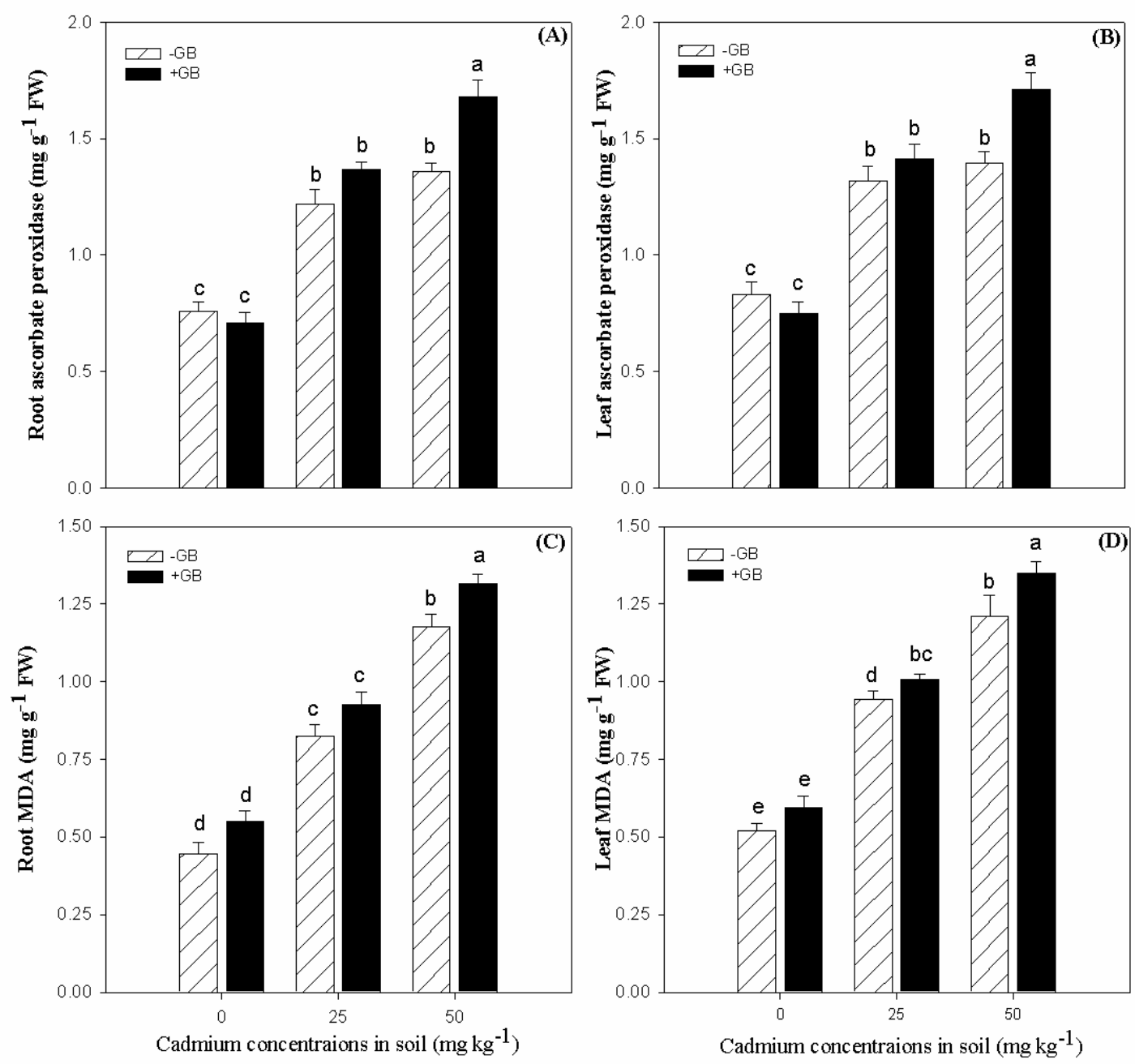

Figure 4. Effect of foliar applied GB on the root and leaf APX and MDA activities of spinach grown in different levels of $C d$ stress. Bars represents the SE of three replications. -: No GB application, +: GB application

\section{Discussion}

The present study was conducted to determine the impact of foliar applied GB on the spinach against $\mathrm{Cd}$ stress. The results indicated that $\mathrm{Cd}$ stress considerably decreased the growth and biomass production of spinach. However, the more reduction in both growth and biomass characters was observed under higher Cd stress. In present study $\mathrm{Cd}$ stress considerably reduced the root and shoot growth of spinach. The reduction in root can be due to the $\mathrm{Cd}$ accumulation in the roots as well as the negative impact of $\mathrm{Cd}$ on root tip which resulted in poor root growth. Moreover, the reduction in shoot growth might be due the changes in cell structures and oxidative damage caused by the $\mathrm{Cd}$. These results are in consistence with the outcomes of Liu et al. (2004) and Sana et al. (2014) they reported that $\mathrm{Cd}$ stress reduced the root and shoot growth through inhibition of cell division and production of ROS in garlic and wheat. The reduction in the fresh and dry mass by the Cd stress might be due to oxidative stress and less root growth, which resulted in poor water and nutrients uptake and therefore led to less biomass production. Earlier, Agami and Mohamed (2013) reported that Cd stress considerably 
reduced the biomass production owing to reduction in root growth and water uptake. In present study foliar applied GB reduced the toxic effects of $\mathrm{Cd}$ stress and led to a significant improvement in plant growth and biomass production. The improvement in growth and biomass by the foliar applied GB might be due to increase in nutrients uptake which resulted in more biomass production under the stress conditions (Shahbaz et al., 2011). Moreover, foliar GB also improved the activities of antioxidant enzymes (Fig. 4) and reduced the uptake of $\mathrm{Cd}$ and therefore, led to a significant increase in the growth and biomass production under the Cd stress (Einset et al., 2008).

In addition, to growth and biomass, $\mathrm{Cd}$ stress also considerably reduced the chlorophyll $\mathrm{a}$ and $\mathrm{b}$ contents. However, increase in Cd stress linearly decreased the concentration of both the chlorophyll $\mathrm{a}$ and $\mathrm{b}$ contents. The reduction in chlorophyll $\mathrm{a}$ and $\mathrm{b}$ contents by the $\mathrm{Cd}$ stress might be due to changes in the chlorophyll structure, and inhibition of pigment synthesis which led to reduction in the chlorophyll $a$ and $b$ contents. Another possible reason for the reduction of chlorophyll $\mathrm{a}$ and $\mathrm{b}$ contents was production of reactive oxygen species (ROS). These findings are comparable with the outcomes of Rasheed et al. (2014) they concluded that Cd stress considerably reduced the chlorophyll contents in wheat owing to changes in chlorophyll structure and production of ROS. The results indicated that foliar applied GB improved the concentration of chlorophyll contents under the Cd stress. The increase in chlorophyll contents by foliar applied GB might be due to reduction in the $\mathrm{Cd}$ uptake and improvement in the activities of anti-oxidant enzymes by the GB which resulted in more chlorophyll a and b contents. Likewise, Wang et al. (2010) noted that foliar application of GB improved the chlorophyll contents under stress conditions.

In present study $\mathrm{Cd}$ concentration in plant parts including roots and leaves was increased with increase in Cd stress. Cd concentration was higher in the spinach roots as compared to the leaves. The increase in the $\mathrm{Cd}$ concentration in roots can be due to precipitation of $\mathrm{Cd}$ into insoluble salts or due to $\mathrm{Cd}$ compartmentalization in root vacuoles. On the other hand, foliar application of GB considerably reduced the concentration of $\mathrm{Cd}$ in the roots and leaves of the spinach. Previously reduction in the heavy metal i.e., $\mathrm{Cd}$ and $\mathrm{Pb}$ in plant parts by foliar applied $\mathrm{GB}$ has been also reported by the Islam et al. (2010) and Hossain et al. (2010). Foliar applied GB protects the cell membrane and prevents the entry of $\mathrm{Cd}$ in the cytoplasm and therefore, led to less concentration of $\mathrm{Cd}$ in plant parts. Earlier, Duman et al. (2011) noticed that foliar applied GB considerably reduced the uptake and accumulation of $\mathrm{Cd}$ in the plant parts. The results indicated that activities of antioxidant enzymes, i.e., APX and MDA in roots and leaves were increased in response to Cd stress. Moreover, foliar applied GB further improved the activities of anti-oxidant enzymes under the $\mathrm{Cd}$ stress. In present study the increase in activities of anti-oxidant enzymes by the foliar applied GB can be attributed to reduction in uptake of $\mathrm{Cd}$ and detoxification of reactive oxygen species which resulted in more activities of the anti-oxidant enzymes. Likewise, in another study Ali et al. (2015) noted that exogenous GB improved the activities of APX under different abiotic stresses.

\section{Conclusion}

In conclusion, $\mathrm{Cd}$ stress considerably reduced the plant growth, biomass production and photosynthetic pigments, and leads to significant $\mathrm{Cd}$ accumulation in plant parts through decreasing the activities of anti-oxidant enzymes. Foliar applied GB improved 
the plant growth and biomass production through reduction in $\mathrm{Cd}$ accumulation and improvement in the activities of anti-oxidant enzymes. Therefore, the foliar applied GB can minimize the health risk by preventing $\mathrm{Cd}$ accumulation in the spinach.

Acknowledgements. This work was supported by the National Key Research and Development Project of China (2016YFD0300208) and the National Natural Science Foundation of China (41661070).

\section{REFERENCES}

[1] Adrees, M., Ali, S., Rizwan, M., Rehman, M. Z., Ibrahim, M., Abbas, F., Farid, M., Qayyum, M. K., Irshad, M. K. (2015): Mechanisms of silicon-mediated alleviation of heavy metal toxicity in plants: a review. - Ecotoxicology and Environmental Safety 119: 186-197.

[2] Agami, R. A., Mohamed, G. F. (2013): Exogenous treatment with indole-3- acetic acid and salicylic acid alleviates cadmium toxicity in wheat seedlings. - Ecotoxicology and Environmental Safety 94: 164-171.

[3] Ali, S., Chaudhary, A., Rizwan, M., Anwar, H. T., Adrees, M., Farid, M., Irshad, M. K., Hayat, T., Anjum, S. A. (2015): Alleviation of chromium toxicity by glycinebetaine is related to elevated antioxidant enzymes and suppressed chromium uptake and oxidative stress in wheat. - Environment Science and Pollution Research 22: 10669-10678.

[4] Arnon, D. I. (1949): Copper enzymes in isolated chloroplasts. Polyphenoloxidase in Beta vulgaris. - Plant physiology 24: 1-15.

[5] Bailly, C., Benamar, A., Corbineau, F., Dome, D. (1996): Changes in malondialdehyde contents and in superoxide dismutase, catalase glutathione reductase activities in sunflower seeds related to accelerated seed aging. - Plant Physiology 97: 104-110.

[6] Bagheri, R., Bashir, H., Ahmad, J., Baig, A., Qureshi, M. I. (2013): Effects of cadmium on leaf proteome of Spinacia oleracea (spinach). - International Journal of Agriculture Food Science and Technology 4: 33-36.

[7] Cao, F., Liu, L., Ibrahim, W., Cai, Y., Wu, F. (2013): Alleviating effects of exogenous glutathione, glycinebetaine, brassinosteroids and salicylic acid on cadmium toxicity in rice seedlings (Oryza Sativa). - Agrotechnology 2:1.

[8] Chen, T. H., Murata, N. (2011): Glycinebetaine protects plants against abiotic stress: mechanisms and biotechnological applications. - Plant Cell and Environment 34: 1-20.

[9] Choppala, G., Saifullah, B. N., Bibi, S., Iqbal, M., Rengel, Z., Ok, Y. S. (2014): Cellular mechanisms in higher plants governing tolerance to cadmium toxicity cellular mechanisms in higher plants governing tolerance. - Critical Reviews in Plant Sciences 33: 1-18.

[10] Dhir, B., Nasim, S. A., Samantary, S., Sarivastva, S. (2012): Assessment of osmolyte accumulation in heavy metal exposed salivinanatans. - International Journal of Botany 8: 153-158.

[11] Duman, F., Aksoy, A., Aydin, Z., Temizgul, R. (2011): Effects of exogenous glycinebetaine and trehalose on cadmium accumulation and biological responses of an aquatic plant (Lemna gibba L.). - Water Air Soil Pollution 217: 545-556.

[12] Einset, J., Winge, P., Bones, A. M., Connolly, E. L. (2008): The FRO2 ferric reductase is required for glycine betaine's effect on chilling tolerance in Arabidopsis roots. Physiologia Plantarum 134: 334-341.

[13] Farooq, M. A., Ali, S., Hameed, A., Bharwana, S. A., Rizwan, M., Ishaque, W., Farid, M., Mahmood, K., Iqbal, Z. (2016): Cadmium stress in cotton seedlings: physiological, photosynthesis and oxidative damages alleviated by glycinebetaine. - South Africain Journal of Botany 104: 61-68.

[14] Giri, J. (2011): Glycinebetaine and abiotic stress tolerance in plants. - Plant Signal Behavior 6: 1746-1751. 
[15] Hasanuzzaman, M., Alam, M. M., Rahman, A., Hasanuzzaman, M., Nahar, K., Fujita, M. (2014): Exogenous proline and glycine betaine mediated upregulation of antioxidant defense and glyoxalase systems provides better protection against salt-induced oxidative stress in two rice (Oryza sativa L.) varieties. - BioMed Research International 2014: 757219.

[16] Hossain, M. A., Hasanuzzaman, M., Fujita, M. (2010): Up-regulation of antioxidant and glyoxalase systems by exogenous glycinebetaine and proline in mung bean confer tolerance to cadmium stress. - Physiology and Molecular Biology of Plants 16: 259-272.

[17] Islam, M. M., Hoque, M. A., Okuma, E., Banu, M. N. A., Shimoishi, Y., Nakamura, Y., Murata, Y. (2010): Exogenous proline and glycinebetaine increase antioxidant enzyme activities and confer tolerance to cadmium stress in cultured tobacco cells. - Journal of Plant Physiology 166: 1587-1597.

[18] Liu, D., Jian, W., Gao, X. (2004): Effect of cadmium on root growth, cell division and nucleoli in root tip cells of garlic. - Biologia Plantra 47: 79-83.

[19] Liu, L., Zhang, X., Zhong, T. (2016): Pollution and health risk assessment of heavy metals in urban soil in China. - Human and Ecology Risk Assessment: An International Journal 22(6): 424-434.

[20] Mäkelä, P., Peltonen, S. P., Jokinen, K., Pehu, E., Setäla, H., Hinkkanen, R., Somersalo, S. (1996): Uptake and translocation of foliar-applied glycinebetaine in crop plants. - Plant Science 121: 221-230.

[21] Molla, M. R., Ali, M. R., Hasanuzzaman, M., Al-Mamun, M. H., Ahmed, A., Nazim, U. D., Rohman, M. M. (2014): Exogenous proline and betaine-induced upregulation of glutathione transferase and glyoxalase $\mathrm{i}$ in lentil (lens culinaris) under drought stress. - Notulae Botanicae Horti Agrobotanici Cluj-Napoca 42: 73-80.

[22] Rehman, M. Z., Rizwan, M., Ghafoor, A., Naeem, A., Ali, S., Sabir, M., Qayyum, M. F. (2015): Effect of inorganic amendments for in situ stabilization of cadmium in contaminated soil and its phyto-availability to wheat and rice under rotation. - Environment Science and Pollution Research 22: 16897-16906.

[23] Rasheed, M., Muhammad, A. A., Iqbal, H., Zulqurnain, H., Uzma, K. (2014): Exogenous proline and glycinebetaine mitigate cadmium stress in two genetically different spring wheat (Triticum aestivum L.) cultivars. - Brazilian Journal of Botany 37(4): 399-406.

[24] Raza, M. A. S., Saleem, M. F., Moazzam, J. M., Khan, I. (2014): Impact of foliar applied glycinebetaine on growth and physiology of wheat (Triticum aestivum L.) under drought. Pakistan Journal of Agriculture Sciences 51: 327-334.

[25] Rizwan, M., Ali, S., Abbas, T., Zia, R. H. M., Keller, C., Wabel, M. I., Ok, Y. S. (2016): Cadmium minimization in wheat: a critical review. - Ecotoxicology and Environmental Safety 130: 43-53.

[26] Sana, R., Iqbal, M., Hussain, I., Rasheed, R., Ashraf, M. A., Mahmood, S., Younas, M, Iqbal, M. Z. (2014): L Chronic cadmium induced oxidative stress not the DNA fragmentation modulates growth in spring wheat (Triticum aestivum). - International Journal of Agriculture and Biology 16: 789-794.

[27] Shahbaz, M., Masood, Y., Perveen, S., Ashraf, M. (2011): Is foliar-applied glycinebetaine effective in mitigating the adverse effects of drought stress on wheat (Triticum aestivum L.). - Journal of Applied Botany and Food Quality 84: 192-199.

[28] Sulpice, M., Gibon, A., Bouchereau, F., Larher, F. (1996): Exogenously supplied glycine betaine in spinach and rapeseed leaf discs: compatibility or non-compatibility. - Plant, Cell and Environment 21: 1285-1292.

[29] Wagner, G. J. (1993): Accumulation of cadmium in crop plants and its consequences to human health. - Advances in Agronomy 51: 173-212.

[30] Wang, G. P., Zhang, X. Y., Li, F., Luo, Y, Wang, W. (2010): Over accumulation of glycinebetaine enhances tolerance to drought and heat stress in wheat leaves in the protection of photosynthesis. - Photosynthetica 48: 117-126. 